\title{
Newton versus Huygens: como (não) ocorreu a disputa entre suas teorias para a luz ${ }^{+*}$
}

Breno Arsioli Moura ${ }^{1}$

Centro de Ciências Naturais e Humanas

Universidade Federal do ABC

Santo André - SP

\section{Resumo}

Este artigo apresenta uma análise crítica da possível disputa entre as teorias sobre luz e cores elaboradas por Newton e Huygens que teria ocorrido entre os séculos XVII e XIX. Com base em diversos estudos historiográficos já realizados sobre o tema, será mostrado que na Historiografia da Ciência a ideia de uma disputa entre as ópticas de Newton e Huygens é considerada ultrapassada. O artigo fornece um apanhado histórico da Óptica no período, oferecendo subsídios para que essa questão seja também problematizada no Ensino, assim como foi na Historiografia da Ciência atual.

Palavras-chave: Newton; Huygens; História da Óptica; Natureza da Luz; História da Ciência.

\begin{abstract}
This paper presents a critical analysis of the supposed dispute between the theories of light and colors elaborated by Newton and Huygens, which would have occurred between the 17th and 19th centuries. From the study of several historiographical analysis already made about this matter, it will be shown that in Historiography of Science the idea of a dispute between Newton's and Huygens' optics is considered outdated. The paper offers a historical approach of the Optics of that period, providing
\end{abstract}

\footnotetext{
${ }^{+}$Newton versus Huygens: how the dispute between their theories of light (did not) occurred

* Recebido: maio de 2015.

Aceito: novembro de 2015.

${ }^{1}$ E-mail: breno.moura@ufabc.edu.br
} 
resources for a critical study also in Science Teaching contexts, as it already happened in current Historiography of Science.

Keywords: Newton; Huygens; History of Optics; Nature of Light; History of Science.

\section{Introdução}

Em discussões sobre episódios da História da Óptica, é comum nos depararmos com a narrativa de que entre os séculos XVII e XVIII houve uma disputa acirrada entre as teorias corpuscular e ondulatória para a luz, respectivamente representadas pelas figuras de Isaac Newton (1642-1727) e Christiaan Huygens (1629-1695). De um lado, Newton defendeu a ideia da luz como uma série de pequenos corpos materiais emitidos pelos corpos luminosos - a teoria corpuscular - e, de outro, Huygens propôs o conceito de pulsos de luz propagados pelo éter, o que é usualmente classificado como uma teoria ondulatória. A disputa só terminou no início do século XIX, com o advento das concepções de Thomas Young (1773-1829) e Augustin Fresnel (1788-1827) e a ascensão definitiva da teoria ondulatória.

De imediato, a propagação irrestrita e acrítica dessa história pode levar, pelo menos, a duas visões a respeito da Óptica no período. A primeira pressupõe que Newton e Huygens competiram em pé de igualdade, ambos tendo apresentado teorias bem fundamentadas e coerentes. Após a morte dos dois, seus seguidores continuaram a travar um árduo embate. A segunda considera que no século XVIII nada se fez em óptica, estando os filósofos naturais do período por demais ocupados em defender uma das duas teorias. Nesse sentido, Young e Fresnel desempenharam um papel fundamental em encerrar um período de esterilidade na Óptica e decretar Huygens vitorioso, confirmando o fim da hegemonia da teoria corpuscular.

No entanto, na perspectiva da Historiografia da Ciência atual, a interpretação dessa história é bastante diferente. Desde a metade do século passado, estudos historiográficos têm mostrado um panorama menos conflituoso entre as teorias corpuscular e ondulatória no período, geralmente reavaliando os papeis de Newton, Huygens, Young e Fresnel nesse processo. A conclusão que emerge da Historiografia da Ciência é a de que o conflito sistemático, prolongado e amplo entre as ideias sobre luz e cores de Newton e Huygens não existiu e, embora essa história ainda seja muito popular, ela já é considerada ultrapassada há décadas pelos historiadores da Ciência.

Neste artigo, nos basearemos em estudos historiográficos nessa temática para subsidiar uma análise crítica do episódio envolvendo a disputa entre as ópticas de Newton e Huygens. Em um primeiro momento, serão analisados alguns aspectos das duas obras principais em Óptica dos dois: o Tratado sobre a Luz (1690) de Huygens e o Óptica (1704) de Newton. Além disso, será discutida a relação pessoal e profissional entre Newton e Huygens no final do século XVII. Em um terceiro momento, torna-se essencial que investiguemos o contexto que se instalou após a publicação dos textos de Newton e Huygens, quem eram seus defensores e quais 
eram seus argumentos a favor ou contra cada uma das teorias. Por fim, abordaremos o papel de Young e Fresnel nesta nova leitura da História da Óptica, buscando redefinir quais foram suas reais influências para a retomada da teoria ondulatória no século XIX e até que ponto se basearam em Huygens ou criticaram Newton.

Serão citados diversos materiais, entre fontes primárias e secundárias da História da Ciência. No caso das fontes que possuem traduções para o português, os títulos serão citados nessa língua. No caso das fontes ainda não traduzidas, os títulos serão citados na língua original e todas as citações a partir delas foram traduzidas livremente.

O presente texto não traz, dessa maneira, conclusões essencialmente novas do ponto de vista da pesquisa em História da Ciência. Procuramos, por outro lado, fornecer subsídios para que essa história passe também a ser problematizada no Ensino de Ciências, assim como foi dentro de sua Historiografia nas últimas décadas.

\section{O Tratado sobre a Luz de Huygens e o Óptica de Newton}

Newton e Huygens eram coetâneos e viveram em uma época bem particular para a Óptica. A invenção de instrumentos como o telescópio e o microscópio no início do século XVII, bem como a descoberta de novos fenômenos ópticos, tais como a difração e os anéis coloridos em filmes finos, despertaram um enorme interesse entre os filósofos naturais da época. Isto fez com que surgisse uma série de teorias para a luz e as cores, com diferenças e semelhanças entre si. No caso de Newton e Huygens, as diferenças entre suas teorias se sobressaíram, não restando praticamente nenhuma semelhança entre elas.

O Tratado sobre a Luz e o Óptica são obras muito distintas e foram redigidas em momentos e contextos diferentes. O Tratado ficou pronto em 1678, mas foi publicado apenas em 1690. O conteúdo do Óptica começou a ser escrito na década de 1670, nos artigos e textos particulares de Newton, mas sua primeira edição apareceu apenas em 1704. A obra de Huygens foi escrita em francês, enquanto a de Newton em inglês. O Tratado não teve traduções e nenhuma edição imediatamente posterior à publicação original ${ }^{2}$. O Óptica teve outras duas edições em inglês, duas em latim e duas em francês, se levarmos em conta apenas o período em que Newton ainda estava vivo ${ }^{3}$. A composição do Tratado teve significativa influência das ideias e métodos de René Descartes (1596-1650). O Óptica, em uma direção diferente, foi influenciado pelo programa de investigação do mundo natural calcado na observação e experimentação proposto por Francis Bacon (1561-1626). Por essas poucas informações, é possível notar que a relação entre as obras de Huygens e Newton não é tão simples quanto possa parecer.

O Tratado sobre a Luz é dividido em seis capítulos, cada um abordando um fenômeno particular: propagação retilínea da luz, reflexão, refração, refração no ar, dupla refração e forma

\footnotetext{
2 O Tratado foi republicado nas Euevres completes (Obras completas) de Huygens, vol. 9. A primeira tradução em inglês apareceu somente em 1912, por Silvanus P. Thompson (HUYGENS, 1962).

${ }^{3}$ Para um catálogo completo das edições, ver Gjersten (1986, p. 413-414).
} 
dos corpos para produzir a refração e a reflexão. O texto é conciso e objetivo. Em algumas dezenas de páginas, Huygens buscou descrever e explicar os principais fenômenos luminosos, baseando-se no conceito da luz como pulsos não periódicos propagados pelo éter. Autores nacionais e internacionais já se dedicaram ao estudo do Tratado (SHAPIRO, 1973; KRAPAS et. $a l .$, 2011), havendo, inclusive, uma tradução completa em português publicada em 1986 (MARTINS, 1986).

Dois aspectos do trabalho de Huygens são relevantes para o enfoque dado neste texto. O primeiro deles é o já mencionado conceito de pulsos não periódicos propagados pelo éter. Huygens não apresentou uma teoria ondulatória, no sentido moderno. Não há no Tratado os conceitos que estamos acostumados a associar a ondas, tais como periodicidade, comprimento de onda ou frequência. Em trechos iniciais do texto, a posição de Huygens ficou evidente: "Como as percussões no centro dessas ondas ${ }^{4}$ não possuem uma sequência regular, também não se deve imaginar que as ondas sigam umas às outras por distâncias iguais [...]" (MARTINS, 1986, p. 21).

A teoria de Huygens enquadra-se mais precisamente em uma concepção vibracional que propriamente ondulatória. Hakfoort (1995, p. 4) salienta que somente com Leonhard Euler (1707-1783), em meados do século XVIII, foi elaborada uma teoria genuinamente ondulatória. A mesma conclusão também está presente nos estudos historiográficos de Bell (1947, p. 191) e Cantor (1983, p. 13). Dessa forma, Huygens não apresenta em seu Tratado qualquer discussão sobre fenômenos que hoje incluímos facilmente à concepção ondulatória para a luz, por exemplo, interferência, difração, cores etc.

Baseando-se em sua concepção de luz como pulsos não periódicos propagados pelo éter, Huygens foi hábil em construir explicações bastante sofisticadas sobre a refração e a reflexão. Por meio do "princípio de Huygens", ele conseguiu derivar o comportamento dos raios de luz nestes dois fenômenos, explicando-os de maneira coerente do ponto de vista geométrico. Embora a essência do argumento de Huygens tenha se tornado obsoleta - principalmente o conceito de éter -, o raciocínio matemático apresentado no Tratado para explicar os fenômenos da refração e reflexão pode ser empregado ainda hoje ${ }^{6}$.

O segundo aspecto relevante do Tratado é a explicação de Huygens para a dupla refração. Segundo Shapiro (1973, p. 207), este é o ponto crucial de toda a argumentação apresentada no texto. Atualmente, a dupla refração é considerada um fenômeno de polarização da luz.

\footnotetext{
${ }^{4}$ Embora defendemos que a teoria de Huygens não é ondulatória, manteremos os termos na forma que foram traduzidos na edição em português do Tratado.

5 O que hoje conhecemos como "princípio de Huygens" se baseia na ideia de que um pulso luminoso gera pulsos secundários à medida que ele se propaga pelo meio etéreo. Para mais detalhes, ver Shapiro (1973, p. 218-27) e Krapas et. al. (2011, p. 133-37).

6 Por exemplo, há uma dedução das leis da refração e reflexão baseadas nesse “princípio” em Halliday et. al. (1996, p. 18-9, 22-3).
} 
Na época, ela havia sido descoberta por Erasmus Bartholinus (1625-1698) ao analisar as refrações no cristal-da-Islândia. Os relatos de Bartholinus tornaram-se públicos em 1669 e logo chamaram a atenção de vários filósofos naturais da época, entre eles Huygens, Robert Hooke (1635-1703) e Newton (MOURA, 2014, p. 4602-4604). Basicamente, o fenômeno mostrava que um raio incidente gerava dois raios refratados no cristal, um ordinário, que obedecia às leis comuns da refração e outro extraordinário, que não obedecia a nenhuma lei conhecida na época.

Huygens explicou a formação dos dois raios partindo da ideia de que havia duas propagações diferentes dos pulsos dentro do cristal. Na refração ordinária, os pulsos se propagariam como ondas no éter presente no cristal. Na refração extraordinária, por sua vez, os pulsos se propagariam como esferoides não somente no éter, mas também nas partículas do cristal. Huygens demonstrou que seu "princípio" valia para ambas emanações dos raios, denotando a validade e harmonia geral de sua teoria para a luz. Ainda que essa ideia não fosse capaz de explicar alguns casos particulares do fenômeno ${ }^{7}$, ela foi possivelmente o principal pilar de sustentação de toda a defesa de Huygens pela concepção vibracional para a luz, em oposição à concepção corpuscular (SHAPIRO, 1973, p. 237). No Tratado, ele comentou:

Tive eu mesmo necessidade de fazer esse estudo, pois as refrações desse cristal pareciam derrubar nossa explicação precedente sobre a refração regular - mas, pelo contrário, ver-se-á que elas a confirmam fortemente, após serem reduzidas ao mesmo princípio (MARTINS, 1986, p. 47).

Embora a dupla refração seja hoje tomada como um caso de polarização da luz - e, assim, coerentemente explicada de acordo com ideias contemporâneas sobre a natureza ondulatória da luz -, Huygens foi um homem de seu tempo e, por isso, abordou o fenômeno com as bases teóricas e metodológicas pertencentes à época. Sua explicação para esse fenômeno está longe de possuir qualquer referência ou semelhança com a explicação atual, mas, para a época, ela era coerente e conseguia dar suporte à concepção vibracional que Huygens defendia.

Esses dois aspectos do Tratado sobre a Luz indicam que a concepção de Huygens não pode ser arbitrariamente classificada como ondulatória, no viés moderno do termo. Além disso, a discussão sobre eles no texto assinala que Huygens parecia mais preocupado em estabelecer elementos-chave de sua teoria que propriamente defendê-la ou criticar teorias adversárias. Eles desempenharam papeis importantes para a sustentação da argumentação de Huygens, embora não sejam sequer conhecidos ou estudados profundamente em contextos de ensino. Para Sabra

\footnotetext{
${ }^{7}$ Huygens descobriu que se um outro cristal-da-Islândia fosse posicionado abaixo do primeiro, os raios que saiam desse tinham um comportamento diferente no segundo. Se os dois cristais estivessem com suas seções retas paralelas uma à outra, os raios que saiam do primeiro mantinham seu tipo de refração no segundo. Isto é, o raio refratado ordinariamente continuaria sendo refratado ordinariamente e o raio refratado extraordinariamente continuaria a ser refratado extraordinariamente. Contudo, se a seção reta de um dos cristais fosse girada a $90^{\circ}$ em relação à seção do outro, o comportamento se invertia. Raios refratados ordinariamente no primeiro eram refratados extraordinariamente no segundo e raios refratados extraordinariamente no primeiro eram refratados ordinariamente no segundo. Em nenhum desses dois casos, haveria uma nova dupla refração. Isso só ocorria se as seções fossem giradas a ângulos não perpendiculares em relação às outras seções. Huygens não soube explicar esse novo fenômeno no Tratado (MOURA, 2014, p. 4602-8).
} 
(1981, p. 229), o único objetivo de Huygens era “dar uma explicação mecânica clara de algumas poucas propriedades [da luz] as quais, ele acreditava, outros filósofos teriam falhado em explicar antes dele".

O Óptica de Newton possui características marcadamente diferentes do Tratado sobre a Luz. A obra foi dividida em três livros, cada um também dividido em partes. O Livro I contém a exposição de Newton sobre a natureza heterogênea dos raios luminosos e das cores dos objetos. Foi nesse livro que ele incluiu seus famosos experimentos com prismas e sua descrição de um telescópio refletor. Silva (1996) e trabalhos correlatos (SILVA; MARTINS, 1997; 2003) trazem diversas análises detalhadas acerca de seu conteúdo. O Livro II contém as observações e explicações sobre os anéis de cores formados em películas finas, como as bolhas de sabão, hoje conhecidos como "anéis de Newton". Moura (2008) e Shapiro (1993) estudaram em profundidade seu conteúdo. Por fim, o Livro III contém o pensamento de Newton sobre a difração da luz, denominada por ele como "inflexão" da luz. As pesquisas de Stuewer (1970) e Hall (1990) ainda são as melhores fontes para compreendermos mais esse aspecto do trabalho de Newton em Óptica. Ainda nesse livro, ele incluiu suas "Questões", uma série de perguntas a respeito de assuntos não completamente discutidos por ele anteriormente. O texto de Anstey (2004) fornece algumas direções sobre as origens das "Questões". De uma perspectiva geral, as obras de Hall (1993) e Sepper (1994) oferecem boas informações sobre a composição, estrutura e conteúdo do Óptica. A tradução completa do livro para a língua portuguesa foi publicada em 1996 (NEWTON, 1996).

Assim como no Tratado, no Óptica também podemos destacar dois pontos relevantes para a discussão apresentada neste texto. O primeiro deles é a concepção corpuscular para a luz. É bem sabido que Newton é popularmente conhecido como o principal defensor da materialidade da luz. Nesse sentido, suas obras teriam sido as grandes expoentes dessa concepção para a luz. Entretanto, estudos historiográficos modernos sobre diversos aspectos da óptica newtoniana apontam para uma conclusão distinta.

Newton, de fato, adotou uma concepção corpuscular para a luz, mas nunca a defendeu abertamente em seus escritos. Shapiro (2002, p. 227-228) comenta que Newton considerava a materialidade da luz como uma "hipótese provável", sugerida pelos vários resultados experimentais que obtivera ao estudar os fenômenos ópticos. Contudo, essas evidências advindas da experimentação ainda seriam "insuficientes" para estabelecer a concepção como algo provado, segundo seus métodos de investigação do mundo natural. Sepper (1994, p. 181) afirma que o objetivo do Óptica não era o "estudo da luz". O livro pareceu mais voltado a trabalhar as diversas características dos fenômenos ópticos do que propriamente discutir a natureza da luz.

Não há ao longo do texto do Óptica uma defesa explícita aos corpúsculos de luz. No Livro I, Newton utilizou o termo "raio de luz", definido de maneira geral como as menores partes da luz e "as que tanto são sucessivas nas mesmas linhas como simultâneas em várias linhas" (NEWTON, 1996, p. 39). No Livro II, ele explicou a refração e a reflexão com base na ideia de "uma mesma força, exercida variadamente em variadas circunstâncias" (Ibid., p. 203), 
mas não a explorou detalhadamente, tampouco considerou abertamente necessário que a luz fosse definida como uma sucessão de partículas propagadas a partir dos corpos luminosos (MOURA, 2008, p. 122-4).

A única parte do Óptica em que Newton falou abertamente sobre a natureza corpuscular da luz foi justamente a mais especulativa: as "Questões" do Livro III. O filósofo natural inglês abordou esse assunto na "Questão 29", perguntando: “Os raios de luz não são corpos minúsculos emitidos pelas substâncias que brilham?” (NEWTON, 1996, p. 271). Newton apresentou em seguida uma série de aspectos que confirmariam essa hipótese, relacionando-os com os diversos fenômenos ópticos discutidos nas partes anteriores do Óptica. Pelo estilo da pergunta - uma afirmação negativa em forma de questão - e pelos vários argumentos colocados logo em seguida, observamos que a resposta implícita de Newton era um notável "Sim, obviamente". O modo de colocar "questões puramente retóricas" (COHEN, 1956, p. 164) mostra que elas serviram não para fazer questionamentos verdadeiros, mas como cartas de alforria para Newton divagar sobre temas que não se enquadrariam na rigidez indutivista imbuída em seu discurso. Nesse sentido, entretanto, conclui-se que o fato de ele ter incluído essa discussão nas "Questões" implica que a natureza da luz não fez parte de sua doutrina sobre luz e cores (SABRA, 1981, p. 312; SHAPIRO, 2002, p. 251)

O segundo aspecto do Óptica é o caráter indutivista impresso por Newton ao longo do texto. Desde os primeiros argumentos, Newton deixou claro que todo seu discurso seria consequência da observação cuidadosa e da realização de experimentos minuciosos. No início do Livro I, ele afirmou: "Meu objetivo neste livro não é explicar as propriedades da luz por hipóteses, mas propô-las e prová-las pelo raciocínio e por experiências, para o que tomarei como premissas as definições e os axiomas que se seguem" (NEWTON, 1996, p. 39). Ao final do Óptica, ele deixou mais claro seu estilo de investigação:

Como na matemática, também na filosofia natural a investigação das coisas difíceis pelo método da análise deve sempre preceder o método da composição. Essa análise consiste em fazer experiências e observações, em tirar conclusões gerais delas por indução e em não admitir objeções contra as conclusões exceto aquelas que decorrem das experiências ou de algumas outras verdades. Pois as hipóteses não devem ser consideradas na filosofia experimental. E, embora a argumentação pela indução a partir de experiências e observações não seja a demonstração de conclusões gerais, ainda assim, é o melhor caminho de argumentação que a natureza das coisas admite, e pode ser considerada tanto mais forte quanto mais geral é a indução (NEWTON, 1996, p. 292).

A própria estrutura do Óptica ressalta seu viés indutivista, em um estudo superficial. No Livro I, temos inicialmente as "Definições", um conjunto de pressupostos e termos que Newton adotou ao longo da obra. Em seguida, vêm os "Axiomas", um conjunto de conhecimentos tomados como verdadeiros, que podem ser vistos como pilares da teoria sobre luz e 
cores que ele construiu no texto. Logo depois, Newton descreveu suas "Proposições", demonstradas "por experiências". Essas demonstrações são, a princípio, muito ilustrativas e a leitura do texto é geralmente agradável. Não há dúvida que Newton foi hábil em discursar sobre o complexo assunto da luz de maneira objetiva e envolvente. De certa maneira, ele pareceu confiante de que seus argumentos poderiam ser aplicados de maneira geral aos fenômenos ópticos, a despeito de qualquer tentativa de se especular sobre a natureza da luz (COHEN, 1956, p. 155). Em suma, saber se a luz era ou não um corpúsculo não seria necessário para aceitar suas explicações como verdadeiras, embora, como já apontamos, era certo que Newton adotou implicitamente a concepção de luz como matéria.

O texto, sem dúvida, é sofisticado, mas o fato de possuir poucas abordagens matemáticas em comparação à sua obra anterior, os Principia ${ }^{8}$, facilitou sua leitura e aceitação por grande parte da comunidade de filósofos naturais da época, sendo ainda hoje considerado um exemplo de aplicação do método indutivo. Todavia, essa visão parece não resistir a um exame historiográfico mais profundo do Óptica.

A estrutura dividida em "Definições", "Axiomas" e "Proposições" não foi empregada apenas no Óptica, mas derivou de seus Principia. Embora os termos sejam os mesmos, a forma como Newton os empregou no Óptica e nos Principia é díspar. No primeiro livro, as proposições colocadas por ele não fazem referência aos axiomas, tampouco elas são demonstradas pela lógica ou geometria como no segundo (COHEN, 1956, p. 154; 2002, p. 166-167). A “demonstração por experimentos" pareceu seguir uma linha nova de raciocínio, calcada exclusivamente na discussão de evidências empíricas para validar as proposições. Dessa forma, o indutivismo que se aplica aos Principia não se aplica ao Óptica.

Além disso, a estrutura seguida por Newton no Livro I não é mantida totalmente nos livros seguintes. No Livro II, por exemplo, não vemos nenhuma "demonstração por experimentos". A primeira e a segunda partes são compostas de um conjunto de observações sobre os "anéis de Newton", a terceira contém apenas proposições e a quarta novamente apresenta observações, dessa vez sobre os anéis coloridos em películas espessas. Por sua vez, o Livro III é composto apenas de uma parte, que inclui somente observações sobre a difração e, no fim, as "Questões".

Não obstante, o programa da indução não foi seguido estrita e rigorosamente por Newton em nenhum dos livros do Óptica. Silva (1996), em sua análise detalhada do conteúdo do Livro I, mostra que muitos argumentos de Newton foram construídos com o uso implícito de hipóteses. Ademais, alguns pormenores dos experimentos realizados por ele não são triviais como seu discurso faz parecer. No Livro II, algo semelhante ocorreu. Shapiro (1993) afirma

\footnotetext{
8 Os Princípios Matemáticos da Filosofia Natural, conhecido como Principia, constituiu o principal texto de Newton sobre mecânica. O livro foi publicado originalmente em 1687.
} 
que Newton se valeu de um método denominado por esse historiador como "transdução", atribuindo a partículas microscópicas do corpo propriedades macroscópicas ${ }^{9}$. Outros problemas deste livro foram apontados em Moura (2008, p. 76-81), tais como as várias suposições sobre a origem dos "estados da luz", conceito criado por Newton para explicar a refração e reflexão alternadas dos raios, que davam origem aos anéis coloridos em filmes finos. No Livro III, exceto as especulativas "Questões", as observações sobre a difração não seguiram passos indutivos simples (STUEWER, 1970) e Newton sequer apresentou proposições, provavelmente devido a seu estudo tardio do fenômeno (HALL, 1990, p. 20).

As breves considerações anteriores acerca do Tratado sobre a Luz e o Óptica mostram que eles são livros muito diferentes, seja em relação à estrutura, ao conteúdo ou às bases teóricas e metodológicas que guiaram sua redação. De um lado, Huygens investiu em uma argumentação balizada na Geometria e no fenômeno da dupla refração. Do outro, Newton enalteceu o papel dos experimentos e das observações, trazendo uma teoria sobre luz fundamentada na heterogeneidade da luz branca e na estreita relação entre luz e corpos. Objetivamente, o Óptica é mais completo que o Tratado. Como aponta Shapiro (1973, p. 245), "a teoria para a luz de Huygens nunca foi uma séria rival a de Newton". Newton apresentou estudos sobre os mais variados fenômenos ópticos conhecidos na época. Huygens, contudo, restringiu-se à refração, reflexão e dupla refração. Claramente, está envolvida nisso a trajetória de cada um na área, além do contexto em que foram publicadas, aspectos que serão discutidos nas seções seguintes. Porém, as diferenças entre as duas obras não apontam para uma vitória do Óptica na eventual disputa, mas para a conclusão de que elas não poderiam competir entre si em um mesmo nível, uma vez que seus propósitos, conteúdos e fundamentos foram muito divergentes.

Por uma via complementar, a própria natureza da luz foi assunto controverso e obscuro tanto no Tratado como no Óptica. A nenhum dos dois textos pode ser atribuída uma defesa coerente da concepção ondulatória e corpuscular da luz. No Tratado, Huygens discutiu uma teoria mais vibracional que ondulatória. Além disso, preocupou-se com o fenômeno da dupla refração e com os conceitos de ondas esféricas e esferoidais. Não discutiu cores, difração ou interferência, todos fenômenos conhecidos e estudados na época, inclusive por defensores da concepção vibracional, como Hooke. No Óptica, Newton não defendeu abertamente a concepção corpuscular, preferindo tratá-la apenas nas "Questões". O viés indutivista latente em uma leitura superficial do texto logo é desconstruído por uma análise mais detalhada. A estrutura linear e pragmática do raciocínio indutivo é cumprida apenas no Livro I, estando aos remendos nos dois outros. Portanto, ao menos pelo estudo das duas principais obras de Huygens e Newton sobre Óptica, parece não ter existido uma disputa entre suas teorias sobre luz.

\footnotetext{
${ }^{9} \mathrm{Na}$ perspectiva newtoniana, podemos dizer que um corpo vermelho (característica macroscópica) possui partículas que refletem raios de cor vermelha (característica microscópica). Porém, não há como demonstrar "por experiências" a validade dessa última proposição. Trata-se, assim, de uma hipótese. No Livro II, Newton utilizou argumentos semelhantes para discutir as cores dos corpos naturais.
} 


\section{Newton versus Huygens no final do século XVII}

Se Newton e Huygens não disputaram a prioridade sobre a natureza da luz por suas obras, talvez eles tenham feito por outros meios, seja por cartas, por intermédio de outros filósofos naturais ou mesmo pessoalmente. Não seria impossível, por esse ponto de vista, imaginar os dois proferindo discursos acalorados na Royal Society em Londres ou na Académie Royale des Sciences em Paris sobre qual concepção deveria ser aceita. Pela perspectiva da historiografia da ciência, porém, o cenário é bem menos turbulento.

Huygens começou a trabalhar com Óptica logo no início de sua carreira na Filosofia Natural, em meados de 1653. Nesses escritos iniciais, a natureza da luz não foi tema de estudo, pois Huygens dedicou-se mais especificamente à Óptica Geométrica. O holandês estudou o funcionamento de lentes, telescópios e microscópios, discutindo leis para o comportamento da luz e fenômenos relacionados à imperfeição de sistemas ópticos, como a aberração cromática e esférica (BOS, 2007, p. 1213-1214). Atualmente, o resultado desses diversos estudos é conhecido como Dioptrica.

A Dioptrica aparentemente nunca foi finalizada. Segundo Southall (1922, p. 211-212), Huygens nunca pensou em publicá-la por achar que sempre poderia incluir mais ideias e descobertas. O texto é composto de vários escritos redigidos entre 1653 e 1692, distribuídos em aproximadamente mil páginas. Uma boa parte desse material foi publicada postumamente, em 1703. A totalidade dos escritos de Huygens foi organizada e publicada entre o final do século XIX e a década de 50 do século XX pela Dutch Society of Sciences. A Dioptrica pode ser consultada em dois fascículos do volume 13 de suas Euvres Complètes (HUYGENS, 1916a; 1916b).

A natureza da luz propriamente começou a ser aventada por Huygens por volta de 1676. Nesse período, ele teria se convencido de que fenômenos ópticos como a refração e a reflexão só poderiam ser explicados por uma concepção de luz como pulsos propagados pelo éter (BOS, 2007, p. 1220). A conclusão dessas ideias viria alguns anos depois, com a leitura do Tratado sobre a Luz perante à Académie Royale des Sciences, em 1679. O Tratado seria publicado mais de uma década depois, em 1690, cinco antes da morte de Huygens.

Newton iniciou seus estudos sobre luz e cores em meados de 1664, quando ainda era estudante na Universidade de Cambridge. Suas primeiras especulações foram registradas em seu caderno de anotações, intitulado Qucestiones Qaedeam Philosophice e publicado integralmente em McGuire e Tamny (1983) ${ }^{10}$. Neste caderno, Newton escreveu em 45 tópicos sobre temas variados, baseados nos textos que estava lendo na época. Em alguns, Newton escreveu pouco; em outros, suas ideias foram tantas que teve expandir suas anotações. Entre os tópicos estão: "Sobre as cores", "Sobre os vegetais", "Sobre os minerais", "Sobre a visão", "Sobre a luz” etc. Já nesses pensamentos iniciais, Newton negou a concepção vibracional da luz, ao dizer que "a luz não pode ocorrer por pressão, pois, nesse caso, enxergaríamos tão bem ou melhor à

10 Outra fonte de consulta é o The Newton Project<http://www.newtonproject.sussex.ac.uk/>. Acesso em: Mai. 2015. Trechos desse caderno foram traduzidos para o português em Cohen e Westfall (2002, p. 22-30). 
noite do que de dia" (NEWTON, 2002, p. 28). Nesse início, não havia ainda uma formalização de uma concepção corpuscular ou um estudo mais aprofundado sobre os fenômenos ópticos, por parte de Newton. Esses escritos são, assim, reflexões de um iniciante na Filosofia Natural.

Em 1666, Newton escreveu outro texto, Of colours, mais específico sobre a luz e as cores. O texto também foi publicado integralmente em McGuire e Tamny (1983) ${ }^{11}$. Nesse ensaio, estão descritos os primeiros estudos sistemáticos de Newton com prismas e sobre o conceito de luz branca como mistura heterogênea de raios coloridos. Ele também analisou a formação dos anéis coloridos em filmes finos ao pressionar dois prismas um contra o outro, além de apresentar um estudo inicial sobre a visão.

As Qxestiones e o Of Colours não foram publicados na época, mantendo-se nos manuscritos pessoais de Newton e de seus herdeiros até a década de 1930. O trabalho que tornou os estudos sobre a luz de Newton conhecidos, além de ele mesmo, foi a "Nova teoria sobre luz e cores", publicada nas Philosophical Transactions da Royal Society em 1672. O texto trouxe como assunto principal a heterogeneidade da luz branca. A "Nova teoria" provocou uma série de críticas e comentários dos filósofos naturais da época, vindos principalmente de Hooke, Ignace Pardies (1636-1673) e Huygens. Esse episódio é analisado detalhadamente na tradução comentada da "Nova teoria" realizada por Silva e Martins (1996). Apontaremos alguns de seus aspectos gerais a seguir.

A publicação da "Nova teoria" em 1672 gerou os primeiros contatos entre Huygens e Newton, por meio da troca de cartas mediadas pelo então secretário da Royal Society, Henry Oldenburgh (1615-1677). Quando o texto foi publicado, Oldenburgh enviou cópias a vários filósofos naturais, entre eles Huygens. Ele teria feito questão de destacar o texto de Newton para que o holandês o lesse primeiro que outros (WESTFALL, 1980, p. 240). Nessa comunicação inicial, Huygens parece não ter notado a importância do conceito de heterogeneidade da luz branca no texto, se atendo à questão das imperfeições em telescópios, também abordada. Após a insistência de Oldenburgh, que destacou esse ponto novamente, Huygens finalmente teria notado a relevância do conceito, o qual considerou ser uma "hipótese" muito provável (SABRA, 1981, p. 268-9). A partir disso, outras cartas foram trocadas entre ele e Newton, em réplicas e tréplicas de comentários a respeitos da teoria newtoniana sobre luz e cores.

As críticas de Huygens parecem ter sido as mais incisivas dentre as recebidas por Newton nesse processo (WESTFALL, 1980, p. 249). Contudo, as discussões entre eles foram, de maneira geral, amenas e respeitosas. Em sua última carta a Newton, Huygens foi polido, preferindo não estender mais a contenda:

\footnotetext{
$11 \mathrm{O}$ texto também pode ser consultado no The Newton Project <http://www.newtonproject.sussex.ac.uk/>. Acesso em: Mai. 2015). Uma parte foi traduzida para o português em Cohen e Westfall (2002, p. 190-5)
} 
Acerca das soluções, dadas pelo Sr. Newton às dúvidas propostas por mim sobre sua Teoria de Cores, haviam pontos que poderiam respondê-las e formar novas dificuldades. Mas, vendo que ele mantém sua opinião com tanta firmeza, eu prefiro não disputar (HUYGENS, 1958, p. 147).

Pouco depois, em 13 de junho de 1673, Newton respondeu à última carta de Huygens, em um tom notadamente impaciente e dessatisfeito:

Sobre o Senhor N. ${ }^{12}$, [em] sua expressão, de que eu mantenho minha doutrina com alguma firmeza, eu confesso [que] foi um pouco desagradável para mim encontrar com objeções as quais já tinham sido respondidas antes, sem ter sido dada a mim a menor razão [sobre] por que aquelas respostas [dadas em outras cartas anteriores] foram insuficientes (NEWTON, 1958, p. 139).

Newton e Huygens não trocaram mais cartas a respeito da "Nova teoria" nos anos seguintes.

Pessoalmente, Newton e Huygens encontraram-se apenas em 1689, por ocasião da visita do segundo a seu irmão, Constantyn Huygens (1628-1697). O encontro ocorreu em 12 de junho, em uma sessão da Royal Society, em que Huygens apresentou seu Tratado sobre a Luz e o Discourse de la cause de la pensateur. Newton teria discutido suas ideias sobre a dupla refração da luz (SHAPIRO, 1989, p. 223). Segundo Westfall (1980, p. 488), os dois se encontraram, pelo menos, mais duas vezes. O relato de um segundo encontro foi dado por Constantyn em seu diário, reproduzido nas Euvres Complètes de Huygens:

[Meu] irmão Christiaen foi junto com o jovem Sr. Hambden ${ }^{13}$ e Faccio Duiller ${ }^{14}$ e Sr. Newton às 7 horas da manhã a Londres, com o propósito de recomendar este último [Newton] ao rei para um lugar vago de regente de uma faculdade em Cambridge (HUYGENS, 1950, p. 249).

Em outro momento, Newton e Huygens teriam discutido suas ideais sobre luz e cores, mas não há registro de comunicações posteriores entre os dois ${ }^{15}$.

Dessa maneira, a historiografia sobre Newton e Huygens indica que não houve um debate generalizado entre os dois no final do século XVII. Certamente existiram conflitos e

\footnotetext{
12 O nome de Huygens nessa e em outras cartas publicadas nas Philosophical Transactions foi substituído por "N".

13 John Hampden (1653-1696).

14 Nicolas Fatio di Duiller (1664-1753).

15 Na década seguinte, Huygens faria comentários sobre os Principia, então recém-publicado. Muitos desses comentários foram baseados em um texto seu anterior, apresentado à Académie Royale des Sciences em 1669. Um dos propósitos de Huygens foi contrapor a teoria da gravitação universal com uma explicação fundamentada na mecânica cartesiana. O produto desses comentários foi publicado junto com o Tratado sobre a luz em 1690 e intitulado Discours de la cause de la pesanteur. Esse texto, bem como suas diferenças em relação às ideias de Newton, foi estudado por Martins (1989).
} 
discussões, principalmente em 1672, mas os estudos parecem sugerir que esse episódio foi um evento normal e inerente à investigação do mundo natural na época. Vale lembrar que, nesse período, Newton não respondeu apenas às críticas de Huygens, mas às de Hooke, Pardies e outros. Além disso, Huygens nem mesmo tinha uma concepção completa sobre a natureza da luz nessa época.

\section{Newton versus Huygens no século XVIII}

A terceira oportunidade de ter havido uma disputa entre as teorias de Newton e Huygens poderia ter ocorrido posteriormente às discussões de 1672 e à publicação de suas obras, dessa vez, contudo, não pelos próprios autores, mas por seus seguidores no século XVIII. Nesse sentido, cabe analisar como foi a repercussão de suas ideias no período.

Em 1695, Huygens morreu em Haia, na Holanda, para onde regressou depois de anos vivendo em Paris, na França. O legado que deixou foi enorme, não apenas em Óptica, mas em outras áreas da Filosofia Natural, como a Mecânica. Contudo, a ascensão das teorias newtonianas nessas duas áreas foi um dos fatores que contribuiu para que suas ideias fossem ignoradas gradualmente. Logo após a publicação do Tratado sobre a Luz, em 1690, a teoria vibracional de Huygens ganhou alguns apoiadores, mas uma década depois, o texto havia sido completamente esquecido (HAKFOORT, 1995, p. 56). Nesse período, apenas um filósofo natural - Antoine Parent (1666-1716) - o estudou minuciosamente. A influência do Tratado teria sido restrita aos estudiosos da dupla refração da luz (SHAPIRO, 1973, p. 245, 257). Na Holanda, país natal de Huygens, eminentes filósofos naturais, como Wilhelm Jacob 's Gravesande (16881742) ou Peter van Musschenbroek (1692-1761) não adotaram sua teoria (BELL, 1947, p. 192). Mesmo a publicação póstuma de sua Dioptrica, em 1703, não chamou a atenção das pessoas (HALL, 1993, p. 199). Na Mecânica, seu Discourse de la cause de la pensanteur também foi desconsiderado (MARTINS, 1989, p. 155).

A ausência da discussão sobre as cores no Tratado foi um dos aspectos criticados por Hooke, seu coetâneo. Em um manuscrito não publicado na época, ele fez diversas críticas ao texto de Huygens, considerando-o muito aquém de uma defesa da concepção vibracional da luz:

Este pensamento do Sr. Fermat ${ }^{16}$ eu confesso [que] foi muito engenhoso e serve muito bem para explicar uma razão da proporção dos senos dos ângulos de refração aos senos dos ângulos de incidência, se esse for o único fenômeno a ser analisado no raio refratado; o qual ambos o Sr. Fermat e o Sr. Huygens parecem considerar, ambos ao mesmo tempo negligenciando outro efeito inteiramente tão notável e significante, o

16 Pierre de Fermat (1601-1655). 
qual é a coloração ou tingimento dos ditos raios refratados, os quais nem o Sr. Fermat, nem o Sr. Huygens ou o Padre Pardy ${ }^{17}$ nem o Padre Angot ${ }^{18}$ de modo algum analisaram (HALL, 1951, p. 221).

Na França, as ideias de Huygens não tiveram repercussão significativa. Neo-cartesianos, como Nicolas Malebranche (1638-1715), Jean-Jacques Dortous de Mairan (1678-1771) e Johann II Bernoulli (1710-1790) não expandiram os preceitos do Tratado ou sequer aceitaram completamente as ideias lá contidas. Embora a defesa ao cartesianismo e a refutação dos resultados experimentais descritos na "Nova teoria sobre luz e cores" tenham sido alguns dos obstáculos iniciais à entrada da óptica newtoniana (GUERLAC, 1981), os franceses não adotaram a teoria de Huygens para fazerem objeções a Newton. Darrigol (2012, p. 139), por exemplo, é enfático ao dizer que Malebranche foi o "cartesiano mais influente na virada dos séculos dezessete e dezoito". Suas ideias e, principalmente, sua autoridade no país aparentemente favoreceram a aceitação da óptica newtoniana, bem como o prosseguimento da tradição cartesiana (Ibid., p. 143).

Teóricos vibracionistas posteriores também não tomaram o Tratado como base para seus estudos. Euler, provavelmente um dos mais importantes defensores da concepção vibracional/ondulatória para a luz no século XVIII, não mencionou Huygens em nenhuma parte de sua Nova teoria lucis et colorum (1746) (HAKFOORT, 1995, p. 73). Em sua detalhada análise do trabalho de Euler, Hakfoort (1995, p. 74-75) aponta várias diferenças entre os escritos dos dois: Huygens estabeleceu pulsos não periódicos propagados pelo éter, Euler propôs a periodicidade; a concepção de matéria de Huygens não era igual à de Euler; esse último via no "princípio de Huygens" a violação da propagação retilínea da luz, uma vez que as ondas secundárias teriam como consequência o espalhamento da luz para todos os lados; Huygens desconsiderou as cores e enfatizou a dupla refração; Euler fez justamente o contrário. Por essas razões, o autor diz que é possível supor que a teoria de Huygens foi pouco atrativa para Euler. Hakfoort (1995, p. 75) ainda sugere que, embora haja uma certa verdade em dizer que Euler expandiu a teoria de pulsos de Huygens em uma teoria ondulatória, o desenvolvimento conceitual dessa última foi mais fundamentado pelos trabalhos de Malebranche e Bernoulli.

Outros teóricos vibracionistas do século XVIII, cujos trabalhos foram conhecidos e lidos na época, como Claude Nicolas Le Cat (1700-1768), Benjamin Franklin (1706-1790), Gowin Knight (1713-1772) e Abraham Bennet (1749-1799), também não utilizaram as ideias de Huygens (CANTOR, 1983, p. 123-9). Em dois textos sobre História da Óptica publicados nas décadas finais desse século, Huygens também foi ignorado. O The History and Present State of Discoveries Relating to Vision, Light and Colours (1772), de Joseph Priestley (17331804), e o verbete Optics para a terceira edição da Encyclopcedia Britannica (1797), escrito por John Robison (1739-1805), citaram muito brevemente Huygens.

\footnotetext{
17 Referência a Pardies.

18 Pierre Angot (1666-1730).
} 
Priestley (1772, p. 137), por exemplo, afirmou que a Dioptrica era um tratado "excelente", mas não chegou a discutir seu conteúdo em detalhes e posicionou Huygens em meio a vários outros teóricos de sua época, sem lhe conferir papel de destaque. Claramente, tanto no caso de Priestley quanto de Robison, essa desconsideração do trabalho de Huygens foi proposital, uma vez que ambos eram newtonianos e não queriam popularizar teorias objetoras à corpuscular (Cantor, 1983; Moura, 2015). Porém, o fato de esses comentadores não terem colocado Huygens em uma posição antagônica à ocupada por Newton indica que eles próprios não viram nas ideias do primeiro uma rival à altura dos argumentos apresentados no Óptica. Esse papel de antagonista foi atribuído geralmente a Descartes, cujas ideias foram analisadas minuciosamente por eles. Os estudos de Pav (1975), Steffens (1977), Cantor (1983) e Hakfoort (1995) sobre a Óptica do século XVIII corroboram essa percepção.

Do outro lado, Newton e sua óptica alcançaram sucesso mais evidente, conquistando seguidores não só na Grã-Bretanha, mas no continente europeu no curso do século XVIII. A publicação do Óptica em 1704 iniciou um período de extensa valorização e popularização das teorias newtonianas sobre luz e cores. Newton já era famoso na época pelos Principia, mas o Óptica trouxe não somente a síntese newtoniana sobre luz e cores, como também o estilo indutivista em evidência (SILVA; MOURA, 2012).

$\mathrm{Na}$ literatura especializada, há muitos trabalhos que investigam esse processo de popularização da filosofia natural newtoniana. Schofield (1970) discute duas fases da influência de Newton. Na primeira delas, os autores se basearam no conceito de forças e ação à distância presentes nos Principia e nas "Questões" do Óptica para fundamentar suas ideias pelo "mecanismo". Na segunda fase, a partir da metade do século, os filósofos voltaram-se aos escritos de Newton sobre o éter, também presentes nas "Questões", inaugurando uma época "materialista" do Newtonianismo. Em outro trabalho (SCHOFIELD, 1978), o autor salienta que não ocorreu apenas um "Newtonianismo" ao longo do século XVIII. Ele identifica, pelo menos, cinco tipos ou variações da influência dos trabalhos de Newton, dentre as quais se destaca o "Newtonianismo holandês", presente em trabalhos como os de "sGravesande e o "Newtonianismo baconiano", refletido nos textos de Voltaire. Cohen (1956), por sua vez, faz um estudo preciso da influência de Newton sobre os filósofos naturais do século XVIII, especialmente Franklin. O autor afirma que o Óptica foi importante para que esses pensadores seguissem uma metodologia de investigação do mundo natural baseada na observação e na experimentação. Dobbs e Jacob (1995) indicam em um raciocínio complementar ao de Cohen (1956) que os newtonianos sintetizaram e expandiram o trabalho de Newton de tal maneira que nem ele próprio se enquadraria na alcunha de newtoniano. Fara (2002) afirma que a autoridade e o prestígio de Newton o transformaram em uma espécie de "herói nacional" na Grã-Bretanha e analisa o processo de sua transformação em "gênio da Ciência". Moura (2008), mais recentemente, explorou a popularização da óptica newtoniana, especialmente do Livro II do Óptica, notando que seu conteúdo foi quase completamente ignorado na primeira metade do século XVIII, por não se enquadrar 
nos modelos mecânicos elaborados no período para explicar os vários fenômenos ópticos conhecidos.

Nos primeiros anos após a publicação do Óptica, comentadores favoráveis a Newton começaram a incluir discussões sobre o conteúdo do livro em seus trabalhos. Por exemplo, no primeiro volume de seu Lexicon Technicum (1705), John Harris (1666-1719) destacou nos verbetes "Luz" e "Cor" as ideias de Newton contidas na "Nova teoria". No segundo volume, publicado em 1715, Harris baseou-se quase inteiramente no conteúdo do Óptica e defendeu abertamente a concepção corpuscular da luz. Ao reproduzir o conteúdo das "Questões", ele transformou as perguntas de Newton em afirmações: "Portanto, os raios de luz são certamente pequenas partículas, realmente emitidas pelo corpo luminoso [...]" (HARRIS, 1723, verb. "Light", s.p., grifo nosso).

Em outros âmbitos da Filosofia Natural, a popularização da óptica newtoniana também foi expandida. John T. Desaguliers (1683-1744) foi um importante conferencista do início do século XVIII e contribuiu para trazer a um público leigo as ideias de Newton. As conferências oferecidas por ele reuniram diversos grupos de pessoas, entre clérigos, artesãos e nobres, tornando-se modelos para conferências de outros filósofos naturais (HANS, 1998, p. 140-1). Schofield (1970, p. 81) pontua que "seria difícil encontrar um homem mais envolvido em todos os aspectos da Filosofia Natural Britânica". Entre os trabalhos de Desaguliers, destacam-se os dois artigos publicados nas Philosophical Transactions em 1716 e 1722 em que reproduziu os experimentos de Newton com prismas, defendendo suas validades, e os livros Physico-Mechanical Lectures (1717) e A Course of Experimental Philosophy (1734-44), que trouxeram os assuntos tratados em suas conferências. No Physico, por exemplo, a materialidade da luz foi considerada um princípio básico e evidente da Óptica:

Que a luz é um corpo, aparece de sua reflexão, refração, composição, divisão, e seu movimento no tempo; mas especialmente por ser propagada em linhas retas, e por ser parada por um obstáculo (o quão fino for, se não transparente), o que mostra que ela não pode ser uma ação sobre o meio, que seria propagada além de um obstáculo, como no caso do som (DESAGULIERS, 1717, p. 42).

As conferências de Desaguliers ajudaram a propagar a imagem das teorias newtonianas como verdades absolutas, construídas unicamente a partir da experimentação (MOURA; SILVA, 2009). Isso fez com que cada vez mais se reforçasse a concepção de que Newton era um grande experimentador e revolucionário. Nos livros populares, voltados a um público leigo, esses aspectos também estiveram presentes. Sobressaem-se entre esses o Newtonianismo per le Dame (1737) de Francesco Algarotti (1712-1764) e os Elementos da Filosofia de Newton de Voltaire (1694-1778), que abordaram elementos da concepção de mundo newtoniana de maneira bastante coloquial e sem argumentação matemática. Ambos foram grandes sucessos de vendas na época de suas publicações, ganhando traduções para outras línguas e várias edições posteriores (CASINI, 1995; MOURA; SILVA, 2015). 
No campo conceitual, alguns autores da primeira metade do século XVIII buscaram aliar os conceitos presentes no Óptica com a mecânica dos Principia. Isso fez com que nesse período, vários modelos mecânicos para explicar os fenômenos ópticos fossem elaborados. "sGravesande, por exemplo, pensou em um "espaço de atração" existindo na superfície que divide dois meios de densidade diferente. Quando o raio de luz entrava nesse "espaço", ele ficaria sujeito à influência de uma força atrativa do corpo mais denso, tendo sua trajetória inicial desviada. Robert Smith (1689-1768) apresentou uma ideia similar, mas com outros elementos. Seu "espaço de atividade" não incluía apenas uma região de atração - que explicava a refração -, mas também uma região de repulsão, que dava conta da reflexão. Embora, a princípio, modelos como esses fossem capazes de resolver problemas básicos da Óptica, eles não resistem a um exame minucioso de suas bases teóricas, pois não conseguem explicar, por exemplo, a reflexão e refração parciais da luz, o que determina suas extensões dentro e fora dos corpos etc. A despeito disso, esses modelos não foram criticados nesses momentos iniciais de propagação da óptica newtoniana (MOURA; SILVA, 2010).

As únicas críticas à óptica newtoniana parecem ter vindo de Robert Green (16781730). Em dois livros publicados em 1712 e 1727, Green considerou as ideias de Newton incoerentes e repleta de falhas. Conforme diz Cantor (1983, p. 218-219, n. 15), Green acreditava que a concepção corpuscular tinha se tornado o ponto central da Filosofia Natural da época, mas rejeitou todas as teorias para a luz que envolviam partículas de matéria. Para ele, a matéria era uma substância heterogênea ativa e todo o espaço era preenchido com um éter indiferenciado e ativo, formando todo o Universo. A luz seria uma ação nesse meio etéreo. Contudo, a falta de expressividade de Green na comunidade de filósofos naturais da época, aliada à obscuridade de seu texto e o crescente prestígio de Newton minaram qualquer tentativa de uma crítica à óptica newtoniana tornar-se significativa aos olhos dos outros.

A partir da segunda metade do século XVIII, o panorama foi modificado por alguns acontecimentos. O surgimento de teorias ondulatórias como a de Euler e o avanço das críticas à concepção corpuscular contribuíram para mudar ligeiramente o cenário (CANTOR, 1983, p. 50-90). Uma das críticas, a título de exemplo, era em relação à detecção do momento dos raios de luz. Em 1772, Priestley relatou em seu History que John Michell (1724-1793) havia realizado experimentos com folhas finas de cobre iluminadas com um feixe concentrado de luz solar. Segundo ele, a lâmina de cobre "começou a se mexer em um movimento lento e bater contra a parte de trás da caixa como antes" (PRIESTLEY, 1772, p. 389). O próprio Priestley, contudo, em trechos posteriores, admitiu implicitamente que os experimentos tinham falhas. Não obstante, ele e outros defensores de Newton os consideravam evidências determinantes da materialidade da luz. Por sua vez, em 1792, Bennet publicou um artigo nas Philosophical Transactions que mostrava um resultado oposto. A partir de experimentos semelhantes ao de Michell, Bennet notou que, embora eles tivessem sido repetidos diversas vezes, ele não percebeu "nenhum movimento distinguível daquele [decorrente] dos efeitos do calor" (BENNET, 1792, p. 87). Porém, enquanto os que defendiam a concepção corpuscular utilizavam os experimentos 
de Michell como suporte, os objetores faziam o mesmo com os experimentos de Bennet (CANTOR, 1983, p. 58).

Nesse período, convém mencionar os estudos historiográficos de Priestley (1772) e Robison (1797), citados anteriormente. Ambos apresentaram a óptica newtoniana como o alicerce para o aperfeiçoamento da compreensão sobre os fenômenos da luz e das cores e criticaram aqueles que negavam sua validade e importância. Priestley (1772, p. 348) afirmou que os "opositores principais de Newton não eram pessoas que tinham elaborado quaisquer hipóteses próprias, as quais eles supostamente poderiam estar atrelados”. Robison (1797, p. 278), em um argumento semelhante, disse:

Sir Isaac Newton mostrou, da maneira mais incontrovertida, a total dissimilaridade entre os fenômenos da visão e as consequências legítimas das ondulações de um fluido elástico. Todas as discussões engenhosas e laboriosas do Sr. Euler não removeram no menor grau as objeções de Newton.

Em nenhum dos autores do século XVIII indicados até aqui, há qualquer alusão de uma disputa entre Newton e Huygens, tanto entre aqueles que defenderam a concepção corpuscular quanto os que defenderam a concepção vibracional/ondulatória. Igualmente, não há indícios de que houve uma disputa muito definida entre as duas concepções. Embora, ao longo do século, a concepção vibracional tenha ganhado adeptos, muitos não conheciam os trabalhos dos outros, sendo esse um dos fatores que explica sua falta de popularidade e desenvolvimento no período (CANTOR, 1983, p. 123). Além disso, a influência cartesiana/huygensiana na GrãBretanha foi pouco sentida, com destaque, porventura, para o trabalho de Jacques Rohault (1618-1672), cujos escritos eram lidos em Cambridge nessa época (Ibid., p. 115). A óptica newtoniana reinava absoluta nas ilhas. Em outros países, pelo contrário, como França, Alemanha e Portugal, demorou algumas décadas até que os escritos de Newton fossem conhecidos, permanecendo o viés cartesiano para a compreensão da natureza e comportamento da luz (GUERLAC, 1981; HAKFOORT, 1995; BERNARDO, 1998). O panorama geral de todo esse contexto sugere que não houve uma disputa sistemática e contínua entre Newton e Huygens ou entre a concepção corpuscular e vibracional/ondulatória. Da mesma forma, sugere que os corpuscularistas e os vibracionistas não ficaram parados, mas buscaram desenvolver, cada qual à sua maneira, as concepções que defendiam.

Um contexto de debate se instalou efetivamente na época seguinte, o século XIX. Contudo, essa polêmica passou longe de ser entre Newton, Huygens e suas teorias sobre luz.

\section{Os trabalhos de Young e Fresnel}

Costuma-se atribuir a Young o papel central para a retomada da concepção ondulatória e a Fresnel o papel de estabelecer sua superioridade perante à concepção corpuscular. Os dois teriam participado de um intenso debate no início do século XIX sobre qual das concepções era correta, sendo que a vitoriosa teria sido a ondulatória. Huygens, enfim, teria vencido Newton. 
No entanto, as conclusões da historiografia moderna são, assim como nos períodos anteriores, muito diferentes. Os estudos de Frankel (1976) e Buchwald (1989) detalham esse episódio e afastam a opinião de que o debate foi tão simples quanto se pensa comumente.

No início do século XIX, a concepção vibracional e a corpuscular já haviam passado por tantas transformações que mal poderiam ser comparadas com aquelas propostas por Huygens e Newton entre o final do século XVII e início do século XVIII. A concepção vibracional começava a dar lugar à ondulatória. A corpuscular assimilou novas propriedades e buscou explicar fenômenos que Newton não poderia imaginar que existiam. Por esses e outros fatores, Huygens e Newton, assim como seus trabalhos, não foram os protagonistas do debate entre as duas concepções.

No início do século XIX, ainda havia uma predominância muito forte da concepção corpuscular, não apenas na Grã-Bretanha, mas em países onde no início do século anterior o viés cartesiano dominava, como a França (FRANKEL, 1976). A óptica corpuscular era ensinada nas universidades e parecia não haver dúvidas de sua validade. Entretanto, os corpuscularistas sabiam de suas falhas e tinham ciência das críticas que vinham recebendo desde a década de 1740. Não havia sido desenvolvida ainda uma lei para as possíveis forças de atração e repulsão entre luz e corpos, por exemplo (CANTOR, 1983, p. 87).

Quando Young começou a trabalhar com Óptica, ele sabia qual era o contexto em que escrevia. Ele estava ciente de que certamente seria criticado por defender uma concepção ondulatória, pois muitos outros antes deles já haviam sido, como Euler. Nessa conjuntura, fazer referência constante a Huygens não ajudaria, uma vez que o holandês já estava esquecido há décadas. Não é surpresa constatar que Young enfrentou enorme resistência e descrença entre os filósofos naturais europeus da época (STEFFENS, 1977, p. 107-136).

Os primeiros argumentos de Young a favor de uma concepção ondulatória foram descritos em uma comunicação de 1800 publicada nas Philosophical Transactions. O tema central da publicação foi, na realidade, o som. Uma das partes deste texto tratou da analogia entre os fenômenos luminosos e os sonoros ${ }^{19}$. Nesse trecho, Young evocou Huygens:

Desde a publicação dos escritos incomparáveis de Sir Isaac Newton, suas doutrinas de emanação de partículas de luz a partir de substâncias lúcidas e da pré-existência formal de raios coloridos na luz branca têm sido quase universalmente aceitas neste país, e pouco combatida em outros. Leonard Euler, por sua vez, em diversos de seus trabalhos, avançou algumas objeções poderosas contra elas, mas não suficientemente poderosas para justificar a reprovação dogmática com a qual ele as trata; e ele deixou aquele sistema de vibrações etéreas, o qual depois de Huygens e alguns outros ele adotou, igualmente suscetível a ataques em várias partes frágeis. Sem querer de-

\footnotetext{
${ }^{19}$ Embora o título do texto seja Outlines of Experiments and Inquiries Relating to Sound and Light, Young dedicou apenas essa parte a uma análise mais detalhada da luz. Todo o restante do artigo trata das propriedades e comportamento das ondas sonoras.
} 
cidir positivamente a respeito da controvérsia, é concebido que algumas considerações possam ser trazidas à tona, as quais podem tender a diminuir o peso das objeções a uma teoria similar à Huygeniana (YOUNG, 1800, p. 125).

Embora tenha citado Huygens, o maior destaque foi dado a Euler nos trechos posteriores. Young criticou o trabalho do suíço, afirmando que a hipótese de Euler sobre como a luz seria transmitida estava "sujeita a fortes objeções" (YOUNG, 1800, p. 126). Em seguida, postulou uma teoria ondulatória inicial e sugeriu que o aparecimento dos "anéis de Newton" pudesse ser análogo à produção de diferentes sons em um tubo de órgão. Nessas especulações iniciais, não havia uma teoria ondulatória totalmente elaborada, que pudesse rivalizar à altura a concepção corpuscular construída e reconstruída desde o século anterior.

Dois anos mais tarde, em 1802, Young publicou outro texto nas Philosophical Transactions $^{20}$, dessa vez, inteiramente voltado à discussão sobre a natureza ondulatória da luz. Nesse texto, também foi proposta abertamente a lei da interferência. Assim como no artigo anterior, Huygens foi citado timidamente em algumas poucas partes do texto. Em um trecho, Young comentou que a teoria ondulatória que iria propor já havia sido sugerida por Euler e, curiosamente, por Newton. Estava envolvida nisso uma estratégia de evitar uma rejeição imediata a suas ideias, uma vez que, em seu entendimento, os argumentos presentes no óptica continham pistas para a sustentação de uma teoria ondulatória. Dessa forma, isso poderia chamar a atenção dos newtonianos da época, de modo que eles não negassem as ideias de Young prontamente (STEFFENS, 1977, p. 120). Percebe-se na passagem abaixo que Huygens não ocupa um lugar de destaque:

Um exame mais extensivo dos vários escritos de Newton tem me mostrado que ele foi de fato o primeiro a sugerir uma teoria tal qual a que eи vou me empenhar a sustentar; que suas opiniões diferem menos desta teoria [ao contrário do] que é agora quase universalmente suposto; e que uma variedade de argumentos tem sido elaborada, como se [quisessem] refutá-lo, podendo ser encontrada de maneira quase similar a partir de seus próprios trabalhos; e isto por ninguém menos que um matemático como Leonard Euler, cujo sistema de luz, até onde sei, tanto foi ou pode ter sido, totalmente emprestado de Newton, Hooke, Huygens e Malebranche (MOURA; BOSS, 2015, p. 4203-4206).

Em outro trecho, Young comentou sobre a explicação de Huygens para a propagação da luz a longas distâncias. Para ele, as ideias do holandês levariam à conclusão de que a luz não poderia se propagar a distâncias consideráveis, dado que as ondulações perderiam força ao longo do caminho.

Agora, para que tal ondulação possa continuar seu progresso a qualquer distância considerável, deve haver em cada parte dela uma tendência a preservar seu próprio movimento em linha reta a partir do centro. Pois, se o excesso de força em qualquer parte fosse comunicado às partículas vizinhas, não há razão pela qual ele não deveria

${ }^{20}$ Este artigo foi traduzido integralmente para o português em Moura e Boss (2015). 
ser logo equalizado ao longo [do caminho], ou, em outras palavras, ser extinto totalmente, visto que os movimentos em direções contrárias naturalmente destruiriam uns aos outros. [...] De fato, a teoria de Huygens explica o caso de uma maneira toleravelmente satisfatória: ele supõe que toda partícula do meio propaga uma ondulação distinta em todas as direções; e que cada efeito geral somente é perceptível onde uma porção de cada ondulação conspira em um mesmo instante. É fácil mostrar que esta ondulação geral procederia em todos os casos retilineamente, com força proporcional. Mas, acerca dessa suposição, parece seguir que uma maior quantidade de força deve ser perdida pela divergência das ondulações parciais que aquela que parece ser consistente com a propagação do efeito a qualquer distância considerável (MOURA; BOSS, 2015, p. 4203-4211).

Enquanto Huygens foi pouco referenciado, Newton ocupou amplo espaço na argumentação de Young. Ele inseriu uma série de trechos do Óptica e de outros escritos pelo inglês, sempre com o intuito de fundamentar sua argumentação. É interessante observar que um dos principais nomes do ressurgimento da concepção ondulatória tenha se baseado extensivamente naquele que se tornou o exemplo de defensor da concepção corpuscular. Young, afinal, parecia nutrir enorme respeito pela figura de Newton e não desprezou ou criticou cegamente suas ideias.

Steffens (1977) e Cantor (1983) ressaltam que o principal articulador da teoria ondulatória para Young foi Euler, e não Huygens. Nota-se, porém, que Young criticou o trabalho do suíço em alguns momentos, acusando-o, inclusive de não ter incluído "nenhuma evidência argumentativa qualquer para a teoria [ondulatória]". Por outro lado, Huygens era visto até mesmo por ele como alguém já "suplantado" por Euler (YOUNG, 1807, p. 480). As maiores referências a Huygens por Young parecem ter surgido em suas revisões dos trabalhos de Pierre-Simon Laplace (1749-1827) sobre dupla refração (CANTOR, 1984, p. 69).

Os vários trabalhos de Young propondo a teoria ondulatória publicados entre $1800 \mathrm{e}$ 1807 foram recebidos com pouco entusiasmo pelos filósofos naturais da época. Alguns, como Henry Brougham (1778-1868), proferiram críticas incisivas e quase ofensivas, acusando Young de ter deturpado a imagem de Newton. No plano geral, suas ideias tornaram-se conhecidas, mas causaram pouco efeito prático para ocasionar uma virada significativa em favor da concepção ondulatória da luz (STEFFENS, 1977, p. 128-136; CANTOR, 1983, p. 140-146; DARRIGOL, 2012, p. 187; MOURA; BOSS, 2015). Em parte, essa recepção morna ao trabalho de Young reflete o contexto britânico da época. A maioria dos filósofos naturais defendia Newton, suas realizações e seu método indutivo. Nesse sentido, havia um forte predomínio dos filósofos naturais escoceses, que contribuíram para propagar a concepção corpuscular da luz e o indutivismo como verdades absolutas da Filosofia Natural, além de minar quaisquer teorias baseadas em hipóteses, como a de Young foi classificada (CANTOR, 1975, p. 116). Contudo, cabe dizer que haviam pessoas dentro da comunidade de corpuscularistas que enxergavam nas ideias de Young e na concepção ondulatória capacidade para explicar alguns fenômenos ópticos, como David Brewster (1781-1868), embora ele não tenha adotado essa concepção em nenhum momento de sua carreira (CANTOR, 1984, p. 70). 
O debate entre os defensores da concepção corpuscular e os da concepção ondulatória instalou-se na França, a partir da década de 1810. Assim como na Grã-Bretanha, havia no país um grupo de filósofos naturais hegemônicos, que utilizavam a filosofia natural newtoniana como base para suas pesquisas sobre o mundo natural. Esse grupo era representado principalmente por Laplace e o que é conhecido hoje como "programa Laplaciano" de pesquisa. Esse "programa" tinha como pressuposto básico a explicação de vários tipos de fenômenos macroscópicos e microscópicos por meio do conceito de forças entre partículas, alicerçado no conteúdo dos Principia e do Óptica de Newton (FOX, 1974, p. 92).

O "programa Laplaciano" atingiu seu auge entre 1805 e 1815, mas começou a ser desenvolvido e aplicado antes, ainda no final do século XVIII. Na Óptica, especificamente, vários de seus adeptos buscaram consolidar a visão corpuscular newtoniana na compreensão dos fenômenos ópticos. O próprio Laplace propôs uma explicação para a refração por meio de forças de curto alcance no quarto volume de seu Traité de Mécanique Céleste, publicado em 1805 (FOX, 1974, p. 99). Além dele, outros eminentes filósofos naturais franceses se juntaram ao "programa" e buscaram expandi-lo, dentre os quais estão René Just Hauy (1743-1822), JeanBaptiste Biot (1774-1862), François Arago (1786-1853), Joseph Louis Gay-Lussac (17781850) e Siméon Denis Poisson (1781-1840).

Em 1808, Étienne-Louis Malus (1775-1812) apresentou ao Institut de France - criado a partir da junção das antigas academias científicas do país - um texto sobre a dupla refração da luz, a fim de concorrer ao prêmio oferecido pelos membros para o melhor trabalho sobre o assunto. No artigo, Malus confirmou a regra de Huygens para a trajetória do raio extraordinário, mas aplicou um viés corpuscularista para explicá-la (BUCHWALD, 1980, p. 361-364). O trabalho de Malus foi premiado e logo depois suas propostas tornaram-se pontos centrais do desenvolvimento da óptica corpuscular segundo o padrão Laplaciano. No caso da dupla refração, a concepção corpuscular parecia se enquadrar perfeitamente, visto que, ao contrário da concepção ondulatória, para a primeira era possível imaginar inúmeras formas para os corpúsculos de luz e, então, utilizá-las para corroborar as evidências experimentais.

$\mathrm{Na}$ época, foram publicadas críticas e teorias alternativas para explicar os fenômenos ópticos tratados segundo o "programa Laplaciano". Entretanto, seus adeptos adotavam um método que se revelou eficaz nesse momento inicial: a rejeição e o menosprezo a todas as críticas. Isso foi possível, entre outras coisas, pelo domínio dos Laplacianos em vários âmbitos da Filosofia Natural francesa, seja no campo educacional seja na pesquisa. Havia, assim, um controle absoluto do que era e poderia ser feito e do que seria publicado nos periódicos administrados por eles (FOX, 1974, p. 107). Entretanto, havia dissidentes.

Em relação à Óptica, provavelmente o mais importante desertor do "programa" foi Arago, que se tornou defensor da concepção ondulatória em meados de 1813 e 1814. Nesse período, não se ouvia falar em Young na França e Huygens era lembrado apenas por suas investigações sobre a dupla refração. Frankel (1976, p. 156-157) aponta que divergências entre 
Arago e Biot sobre a prioridade a respeito de estudos de polarização ocorridas em 1812 desempenharam um papel importante no afastamento de Arago dos Laplacianos, possivelmente fazendo com que ele ficasse mais aberto a novas ideias sobre o comportamento da luz.

Arago pertencia a uma nova classe de filósofos naturais que não haviam sido doutrinados completamente no "programa Laplaciano" desde o final do século XVIII. Isso contribuiu para que, gradualmente, se formasse um grupo de objetores às ideias de Laplace e seus seguidores e, consequentemente, à concepção corpuscular para a luz (FOX, 1974, p. 110). Foi nesse cenário que os trabalhos de Fresnel surgiram, impulsionados pelo constante apoio de Arago e auxiliados pelo fato de que este último ocupava posições estratégicas dentro da comunidade de filosóficos naturais franceses.

Fresnel trabalhava como engenheiro para o governo francês na época do auge do "programa Laplaciano". Sua ausência de Paris e do circuito filosófico francês possivelmente teve um papel importante para que ele não fosse inserido no viés corpuscular preponderante. $\mathrm{O}$ trabalho como engenheiro não lhe dava tempo para se dedicar à pesquisa, mas ocasionalmente lhe eram oferecidas licenças para realizar seus estudos. A afeição à concepção ondulatória aparentemente foi construída sem inspiração em seus defensores anteriores. Fresnel pode ter entrado em contato com as ideias de Huygens e Euler, mas isso é questionável. O mesmo pode ser dito sobre Young, uma vez que tomou ciência de suas ideias quando já estava embrenhado em seus próprios estudos (SILLIMAN, 2007, p. 862).

Em 1815, já próximo de Arago, Fresnel redigiu dois ensaios sobre a difração, sendo um deles publicado nos Annales de Chimie et de Physique no ano seguinte. A atuação de Arago foi essencial, já que como articulador das ideias de Fresnel nas reuniões do Institut e como editor dos Annales, ele facilitou a entrada da concepção ondulatória em um meio dominado por corpuscularistas (FRANKEL, 1976, p. 158). Com alto rigor matemático e balizado por uma coerente teoria ondulatória para a luz, o trabalho de Fresnel chamou a atenção.

Um momento crucial ocorreu em 1817, quando os membros do Institut decidiram dar um prêmio ao melhor trabalho sobre difração, nos mesmos moldes do prêmio de 1808, dado a Malus pela dupla refração. Na comissão julgadora, quatro defensores da concepção corpuscular - Biot, Laplace, Poisson e Gay-Lussac - e um defensor da concepção ondulatória, Arago. Além do trabalho de Fresnel, apenas outro trabalho de um autor desconhecido foi submetido. Ainda que o contexto fosse totalmente desfavorável a Fresnel, ele foi agraciado com o prêmio (FRANKEL, 1976, p. 161-2). Nos anos seguintes, ele apresentou propostas para outros fenômenos baseadas em uma teoria ondulatória, desenvolveu ainda mais a matemática envolvida em seus argumentos e respondeu às críticas que partiam dos corpuscularistas, além de fazer as suas próprias a eles (DARRIGOL, 2012, p. 216-220)

$\mathrm{Na}$ Grã-Bretanha, também se desenvolvia aos poucos um grupo de filósofos naturais que divergia da linha de pesquisa comum em Óptica, baseada na concepção corpuscular. Eram, em grande parte, teóricos que começaram a trabalhar extensivamente com o desenvolvimento 
da Matemática Analítica, constituindo uma nova classe de pensadores, que aliavam a Matemática Aplicada e a Física-Matemática (CANTOR, 1975, p. 113). Entre esses indivíduos, nomes como John Herschel (1792-1871), George B. Airy (1801-1892) e William Whewell (17941866) destacaram-se como figuras importantes para a abertura da Filosofia Natural britânica a ideias vindas do continente. Nessas primeiras décadas do século XIX, parecia haver um sentimento de que a Filosofia Natural nas ilhas cada vez mais decaía em qualidade. A prosperidade da Filosofia Natural francesa foi admirada pelos britânicos, que buscavam nela uma certa inspiração. Charles Babbage (1791-1871) e Brewster, na década de 1830, chegaram a escrever ensaios sobre o declínio de seus conterrâneos no desenvolvimento da Filosofia Natural (FOX, 1974, p. 90, n. 2).

A introdução dos estudos de Fresnel nas ilhas britânicas ocorreu em meados da década de 1820 (CANTOR, 1983, p. 159). Apoiada pelas publicações favoráveis de Airy e Herschel por volta de 1830, por exemplo, a concepção ondulatória começou a angariar simpatizantes pelo país, muitos deles novos cientistas que não pertenciam ou não foram educados segundo as diretrizes da concepção corpuscular. A escalada progressiva da concepção ondulatória provocou reações dos corpuscularistas das mais diversas. Enquanto que, no início do século, eles puderam desfrutar de relativa calmaria e ignorar os fracos desenvolvimentos dos proponentes de teorias ondulatórias, as circunstâncias já não eram mais as mesmas. Viu-se, então, uma série de tentativas - a maioria, frustrada - de salvar a concepção corpuscular (BUCHWALD, 1989).

Com o embate invertido em favor dos defensores da concepção ondulatória, os corpuscularistas se viram cada vez mais acuados e com o número de apoiadores reduzido drasticamente. Embora alguns aceitassem que a concepção ondulatória era eficaz para compreender os fenômenos ópticos, como Brewster, eles buscaram até o fim do embate estabelecer a validade da concepção corpuscular, seja por meio de experimentos seja afirmando que metodologicamente os modos de investigação que sustentavam as teorias ondulatórias não eram corretos (CANTOR, 1975, p. 119). Aos poucos, o embate foi se esvaecendo e, entre 1840 e 1850, poucos aceitavam a materialidade da luz.

De uma perspectiva geral, é possível notar que a disputa entre aqueles que defendiam a concepção corpuscular e os que defendiam a concepção ondulatória não envolveu Newton ou Huygens. A Óptica na época estava muito mais avançada do que esses dois filósofos naturais jamais poderiam prever.

\section{Conclusão}

Quando Huygens publicou seu Tratado sobre a Luz em 1690 e Newton seu Óptica em 1704, é provável que nenhum dos dois imaginasse que eles seriam protagonistas de uma disputa que nunca existiu, de fato, em grande escala. Huygens teve seguidores nos momentos imediatamente posteriores à publicação de seu texto, mas eles não foram muitos e, em geral, a rejeição foi maior que a aceitação. Newton, pelo contrário, adquiriu admiradores não só nas ilhas britânicas, mas no continente, vendo gradualmente suas ideias se disseminarem e se estabelecerem 
como pilares para o desenvolvimento da Óptica no século XVIII. Contudo, a rápida adesão e transformação das ideias newtonianas fizeram com que o conteúdo do Óptica fosse modificado de maneira que pouco se assemelhava ao seu propósito e fundamento originais. No século XIX, quando a disputa efetivamente ocorreu na França e depois na Grã-Bretanha, os filósofos naturais que dela participaram não se referiam somente ao Óptica ou mesmo ao Tratado. Huygens e Newton haviam se tornado peças de decoração em meio a tantos desenvolvimentos sucessivos das concepções corpuscular e ondulatória.

Se a Historiografia da Ciência atual nos diz que não houve uma disputa entre Newton e Huygens, qual seria a fonte dessa informação? É difícil precisar a origem exata dessa anedota, mas é possível especular algumas possibilidades.

Cantor (1978) argumenta que os trabalhos de Whewell, escritos na década de 1830, exerceram grande influência na interpretação sobre a História da Óptica nos séculos predecessores. Como apontamos anteriormente, Whewell pertencia ao grupo que começou a defender a concepção ondulatória e a criticar a corpuscular. O inglês escreveu vários textos historiográficos na época, relatando, entre outras coisas, o desenvolvimento da Óptica até os seus dias. Em seu History of the Inductive Sciences, ele dividiu o percurso histórico da Óptica em Prelúdio, Época indutiva e Sequência, tomando como referência aos trabalhos de Young e Fresnel (CANTOR, 1978, p. 2). Ao comentar sobre o Prelúdio, período entre os séculos XVII e XVIII, Whewell não poupou elogios a Huygens:

Mas a pessoa que é geralmente, e com justiça, considerada como a grande autora da teoria ondulatória no período agora discutido [Prelúdio a Young e Fresnel], é Huyghens, cujo Traité de la Lumiere, contendo um desenvolvimento dessa teoria, foi escrito em 1678, embora não publicado até 1690. [...] Pela ajuda dessa concepção [ondulatória], Huyghens deu uma explicação perfeitamente satisfatória e correta das leis da reflexão e refração. E ele também aplicou a mesma teoria, como nós vimos, à dupla refração do cristal da Islândia com grande sagacidade e sucesso (WHEWELL, 1837, p. 392-393).

Whewell também comentou sobre a trajetória da concepção ondulatória após Huygens:

A teoria ondulatória, deste período até o nosso, foi infeliz em sua carreira. Não que tenha sido destituída de defensores, mas esses não eram experimentadores [...]. E a grande autoridade do período, Newton, adotou a hipótese oposta, aquela da emissão [...] (WHEWELL, 1837, p. 394).

Em seguida, ele abordou a suposta batalha entre as duas concepções para a luz:

A teoria da emissão foi, contudo, adotada da maneira mais enérgica pelos discípulos de Newton. [...] Por outro lado, a teoria ondulatória foi mantida por ninguém menos que uma pessoa como Euler. E a guerra entre as duas opiniões foi continuada com enorme seriedade (WHEWELL, 1837, p. 398). 
A discussão de Whewell é claramente enviesada pelo contexto da época e por suas preferências teóricas. Sua visão favorável ao desenvolvimento da concepção ondulatória pretendeu traçar um caminho menos monótono e mais glorioso. A título de comparação, o History de Priestley possuiu praticamente a mesma estrutura do texto de Whewell, mas apresentou uma reconstrução da História da Óptica extremamente positiva para a concepção corpuscular.

A análise de Cantor (1978) mostra que a argumentação de Whewell no History influenciou muitos historiadores da ciência desde o século XIX, chegando até o período atual. O autor aponta vários estudos historiográficos modernos que se basearam nessa percepção, atribuindo aos séculos XVII e XIX o auge do desenvolvimento da Óptica e ao século XVIII seu período mais infértil, por estar imbuído totalmente no pensamento newtoniano. Nas seções anteriores, observamos que todos esses períodos foram relevantes para o desenvolvimento da Óptica. Nosso entendimento é que essa percepção também contribuiu para consolidar a crença de que Newton e Huygens disputaram a prioridade em relação à natureza da luz.

Sem querer encerrar o tema com uma interpretação definitiva, a discussão apresentada nesse trabalho buscou expor elementos que contrapõem a ideia de uma possível disputa entre as teorias sobre luz de Newton e Huygens. As evidências trazidas a partir da Historiografia da Ciência levam à conclusão de que não parece adequado reduzir o embate entre a concepção corpuscular e ondulatória da luz entre dois pensadores ou entre dois trabalhos apenas. Da mesma maneira, não se pode desmerecer a importância dos trabalhos de Newton e Huygens para a Óptica. Suas teorias contribuíram para o desenvolvimento tanto da concepção corpuscular quanto da ondulatória, porém elas não foram as únicas desenvolvidas. Nos 150 anos que se passaram entre o final do século XVII e início do século XIX, muitos fatores desempenharam papéis importantes nessa questão. Levá-los em consideração e discuti-los, principalmente em contexto de ensino, pode ilustrar que o embate entre teorias divergentes não é trivial e envolve considerar muitos mais elementos que uma abordagem popular geralmente considera.

\section{Agradecimentos}

O autor agradece ao apoio da Fundação de Amparo à Pesquisa do Estado de São Paulo (FAPESP) em diferentes momentos desta pesquisa.

\section{Referências bibliográficas}

ANSTEY, P. R. The methodological origins of Newton's queries. Studies in History and Philosophy of Science, v. 35, p. 247-269, 2004.

BELL, A.E. Christiann Huygens and the development of Science in the seventeenth century. London: Edward Arnold \& Co., 1947. 218p. 
BENNET, A. A newton suspension of the magnetic needle, intended for the discovery of minute quantities of magnetic attraction: also an air vane of great sensitivity; with new experiments on the magnetism of iron fillings and brass. Philosophical Transactions, v. 82, p. 81-98, 1792.

BERNARDO, L. M. Concepções sobre a natureza da luz no século XVIII em Portugal. Revista da Sociedade Brasileira de História da Ciência, n. 19, p. 3-12, 1998.

BOS, H.J.M. Huygens, Christiaan. In: BENJAMIN, C. (Ed.). Dicionário de Biografias Científicas. Rio de Janeiro: Contraponto, 2007. p. 1207-1223.

BUCHWALD, J. Z. Experimental investigations of double refraction from Huygens to Malus. Archives for History of Exact Sciences, v. 21, p. 311-373, 1980.

. The rise of the wave theory of light. Chicago: University of Chicago Press, 1989. 498p.

CANTOR, G. N. The reception of the wave theory of light in Britain: a case study illustrating the role of methodology in scientific debate. Historical Studies in the Physical Sciences, v. 6, p. 109-32, 1975.

. The historiography of Georgian optics. History of Science, v. xvi, p. 1-21, 1978.

. Optics after Newton - theories of light in Britain and Ireland, 1704-1840. Manchester: Manchester University Press, 1983. 256p.

. Brewster on the nature of light. In: MORRISON-LOW, A. D.; CHRISTIE, J. R. R.

'Martyr of Science': Sir David Brewster 1781-1868. Edinburgh: The Royal Scottish Museum, 1984. p. 67-76.

CASINI, P. Newton e a consciência europeia. Tradução: Roberto Leal Ferreira. São Paulo: Editora da Unesp, 1995. 253p.

COHEN, I. B. Franklin and Newton: an inquiry into speculative Newtonian experimental science and Franklin's work in electricity. Philadelphia: American Philosophical Society, 1956. $657 \mathrm{p}$.

. O método e o estilo de Newton. In: COHEN, I. B.; WESTFALL, R. (Org.). Newton: textos, antecedentes e comentários. Rio de Janeiro: Contraponto/UERJ, 2002. parte 2. p. 16483.

COHEN, I. B.; WESTFALL, R. (Org.). Newton: textos, antecedentes e comentários. Rio de Janeiro: Contraponto/UERJ, 2002. 524p.

DARRIGOL, O. A history of optics from Greek Antiquity to the Nineteenth Century. Oxford: Oxford University Press, 2012. 327p. 
DESAGUliERS, J. T. Physico-mechanical lectures. Or, an account of what is explain'd and demonstrates in the course of mechanical and experimental philosophy. London: [s.n.], 1717. 80p.

DOBBS, B. J. T.; JACOB, M. Newton and the culture of newtonianism. New York: Humanity Books, 1995. 139p.

FARA, P. Newton - the making of genius. New York: Columbia University Press, 2002. 384p.

FOX, R. The rise and fall of Laplacian physics. Historical Studies in the Physical Sciences, v. 4, p. 89-136, 1974.

FRANKEL, E. Corpuscular optics and the wave theory of light: the science and politics of a revolution in physics. Social Studies of Science, v. 6, n. 2, p. 141-84, 1976.

GJERSTEN, G. The Newton handbook. London: Routledge \& Kegan Paul, 1986. 680p.

GUERLAC, H. Newton on the continent. Ithaca: Cornell University Press, 1981. 169p.

HAKFOORT, C. Optics in the age of Euler - conceptions of the nature of light, 1700-1795. Cambridge: Cambridge University Press, 1995. 256p.

HALL, A.R. Two unpublished lectures of Robert Hooke. Isis, v. 42, n. 3, p. 219-230, 1951. . Beyond the fringe: diffraction as seen by Grimaldi, Fabri, Hooke and Newton. Notes and Records of the Royal Society of London, v. 44, n. 1, p. 13-23, 1990.

All was light: an introduction to Newton's “Opticks". Oxford: Claredon Press, 1993. 264p.

HALLIDAY, D.; RESNICK, R.; KRANE, K. S. Física 4. 4. ed. Rio de Janeiro: LTC Editora, 1996. 338p.

HANS, N. New trends in education in the 18th century. London: Routledge, 1998. 261p.

HARRIS, J. Lexicon Technicum; or, an universal English dictionary of arts and sciences, explaining not only the terms of art, but the arts themselves. $2^{\text {nd }}$ ed. London: [s.n.], 1723. v. 2.

HUYGENS, C. GEuvres complètes de Christiann Huygens. T. 13, Fascicule I. Haye : Société Hollandaise des Sciences, 1916a. 432p.

. Euvres complètes de Christiann Huygens. T. 13, Fascicule II. Haye : Société Hollandaise des Sciences, 1916b. 904p.

. Euvres complètes de Christiann Huygens. T. 22. Haye : Société Hollandaise des Sciences, 1950. 921p. 
An answer (to the former Letter) written to the Publisher June 10.1673 by the same Parisian Philosopher, that was lately said to have written the Letter already extant in $\mathrm{N}^{\circ} 96$, $\mathrm{p}$. 6086. In: COHEN, I. B.; SCHOFIELD, R. E. (Ed.). Isaac Newton's papers and letters on Natural Philosophy. Cambridge-MA: Harvard University Press, 1958, chap. 2, p. 147.

. Treatise on light. Translated by: Silvanus P. Thompson. New York: Dover Publications, 1962. 128p.

KRAPAS, S.; QUEIROZ, G. R. P. C.; UZÊDA, D. O Tratado sobre a luz de Huygens: comentários. Caderno Brasileiro de Ensino de Física, v. 28, n. 1, p. 123-151, abr. 2011.

MARTINS, R. A. Tratado sobre a luz. Caderno de História e Filosofia da Ciência, suplemento 4, p. 3-99, 1986.

. Huygens e a gravitação newtoniana. Cadernos de História e Filosofia da Ciência, v. 1, n. 2, p. 151-184, 1989.

McGUIRRE, J. E.; TAMNY, M. (Ed.). Certain philosophical questions: Newton's Trinity notebook. Cambridge: Cambridge University Press, 1983. 532p.

MOURA, B. A. A aceitação da óptica newtoniana no século XVIII: subsídios para discutir a natureza da ciência no ensino. 2008. 205f. Dissertação (Mestrado em Ensino de Ciências) Instituto de Física, Faculdade de Educação, Universidade de São Paulo, São Paulo.

Isaac Newton e a dupla refração da luz. Revista Brasileira de Ensino de Física, v. 36, n. 4, artigo ${ }^{\circ} 4602,2014$.

MOURA, B. A.; SILVA. C. C. Desaguliers e a divulgação da óptica de Newton no século XVIII. In: BELTRAN, M. H. R. et. al. (Org.). História da Ciência e Ensino: propostas, tendências e construção de interfaces. São Paulo: Editora Livraria da Física, 2009. p. 1-5.

Forças entre luz e matéria: modelos mecânicos da óptica corpuscular no início do século XVIII. In: MARTINS, R.A. et. al. (Ed.). Filosofia e História da Ciência no Cone Sul: seleção de trabalhos do $6^{\circ}$ encontro. Campinas: Associação de Filosofia e História da Ciência do Cone Sul (AFHIC), 2010. p. 136-42.

. Voltaire e Algarotti: divulgadores da óptica de Newton na Europa do século XVIII. Scientiae Studia, v. 13, n. 2, p. 397-423, 2015.

MOURA, B. A.; BOSS, S. L. B. Thomas Young e o resgate da teoria ondulatória da luz: uma tradução comentada de sua Teoria sobre Luz e Cores. Revista Brasileira de Ensino de Física, v. 37, n. 4, artigo $\mathrm{n}^{\circ} 4203,2015$.

NEWTON, I. Mr. Newton answer to the foregoing letter further explaining his theory of light and colors, and particularly that of whiteness; together with his continued hopes of perfecting 
telescopes by reflections rather than refractions. In: COHEN, I. B.; SCHOFIELD, R. E. (Ed.). Isaac Newton's papers and letters on Natural Philosophy. Cambridge-MA: Harvard University Press, 1958, chap. 2, p. 137-42.

Óptica. Tradução: André K. T. Assis. São Paulo: Edusp, 1996. 296p.

. A hipótese da luz. In: COHEN, I. B.; WESTFALL, R. (Org.). Newton: textos, antecedentes e comentários. Rio de Janeiro: Contraponto/UERJ, 2002, parte 1, p. 30-54.

PAV, P. A. Eighteenth century optics: the Cartesian-Newtonian conflict. Applied Optics, v. 14, n. 12, p. 3102-8, 1975.

PRIESTLEY, J. The history and present state of discoveries relating to vision, light and colours. London: [s.n.], 1772. v. 1.

ROBISON, J. Optics. In: Encyclopædia Britannica. Edinburgh: [s.n.], 1797. p. 231-364. v. 13.

SABRA, A. I. Theories of light from Descartes to Newton. London: Cambridge University Press, 1981. 363p.

SCHOFIELD, R. E. Mechanism and materialism: British natural philosophy in an age of reason. Princeton: Princeton University Press, 1970. 336p.

. An evolutionary taxonomy of eighteenth-century Newtonianisms. Studies in Eighteenth Century Culture, v. 7, p. 175-92, 1978.

SEPPER, D. L. Newton's optical writings: a guided study. New Brunswick: Rutgers University Press, 1994. 223p.

SHAPIRO, A. E. Kinematic optics: a study of the wave theory of light in the setenteenth century. Archives for the History of Exact Sciences, v. 11, p. 134-266, 1973.

. Huygens' 'Traite de la Lumiere' and Newton's 'Opticks': pursuing and eschewing hypothesis. Notes and Records of the Royal Society of London, v. 43, n. 2, p. 223-247, 1989.

. Fits, passions, and paroxysms. Cambridge: Cambridge University Press, 1993. $420 \mathrm{p}$.

. Newton's optics and atomism. In: COHEN, I. B.; SMITH, G. E. (Ed.). The Cambridge Companion to Newton. Cambridge: Cambridge University Press, 2002, chap. 7, p. 227-255.

SILLIMAN, R. H. Fresnel, Augustin. In: BENJAMIN, C. (ed.). Dicionário de Biografias Científicas. Rio de Janeiro: Contraponto, 2007, p. 860-866. 
SILVA, C. C. A teoria das cores de Newton: um estudo crítico do Livro I do Opticks. 1996. 132f. Dissertação (Mestrado em Física) - Instituto de Física “Gleb Wataghin”, Universidade Estadual de Campinas, Campinas.

SILVA, C. C.; MARTINS, R. A. A "Nova teoria sobre luz e cores" de Isaac Newton: uma tradução comentada. Revista Brasileira de Ensino de Física, v. 18, n. 4, p. 313-327, 1996.

A teoria das cores de Newton e as críticas de Hooke. In: ENCONTRO DE PESQUISA EM ENSINO DE FÍSICA, 5, 1996, Águas de Lindoia. Atas... Belo Horizonte: UFMG/CECIMIG/FAE, 1997, p. 230-237.

. A teoria das cores de Newton: um exemplo do uso da história da ciência em sala de aula. Ciência \& Educação, v. 9, n. 1, p. 53-65, 2003.

SILVA, C. C.; MOURA, B. A. Science and society: the case of acceptance of Newtonian optics in the Eighteenth Century. Science \& Education, v. 21, p. 1317-1335, 2012.

SOUTHALL, J. P. C. Huygens' Dioptrica. Bulletin of the American Mathematical Society, v. 28, n. 4 , p. 211-214, 1922.

STEFFENS, H. The development of Newtonian optics in England. New York: Science History Publications/USA, 1977. 190p.

STUEWER, R. H. A critical analysis of Newton's work on diffraction. Isis, v. 61, n. 2, p. 188$205,1970$.

WESTFALL, R. Never at rest, a biography of Isaac Newton. Cambridge: Cambridge University Press, 1980. 928p.

YOUNG, T. Outlines of experiments and inquiries respecting sound and light. By Thomas Young, M. D. F. R. S. In a letter to Edward Whitaker Gray, M. D. Sec. R. S. Philosphical Transactions, v. 90, p. 106-150, 1800.

A course of lectures on Natural Philosophy and the Mechanical Arts. London: [s.n.], 1807. 796p. v. 1. 